\title{
Características bioquímicas y acción biológica de una hemorragina del veneno de Bothrops brazili
}

\author{
MARTÍN ISLA, ORESTES MÁLAGA, ARMANDO YARLEQUÉ \\ Laboratorio de Biología Molecular, Facultad de Ciencias Biológicas - UNMSM.
}

\begin{abstract}
RESUMEN
OBJETIVO: Caracterizar la hemorragina aislada de B. brazili y determinar si el suero antibotrópico polivalente es capaz de neutralizarlo. MATERIAL Y MÉTODOS: Se ha purificado una hemorragina del veneno de Bothrops brazili a través de dos pasos cromatográficos en Sephadex G-100 y CM Sephadex C50 , usando buffer acetato de amonio 0,05M pH 7. En este último sistema, la proteína fue eluida con $\mathrm{NaCl}$ 0,3M y el análisis electroforético en PAGE-SDS mostró una sola banda proteica. Usando caseína como substrato se determinó una purificación de 8,4 veces, habiéndose calculado la dosis hemorrágica mínima (DHM) en 6,61 ug usando ratones albinos. RESULTADOS: El análisis de carbohidratos asociados a la hemorragina reveló un contenido de $8,05 \%$ de hexosas, $11,62 \%$ de hexosamina y $0,69 \%$ de ácido siálico, en tanto que su resistencia térmica fue registrada hasta $50^{\circ} \mathrm{C}$ por 10 minutos, ya que temperaturas mayores la inactivaron. La hemorragina fue muy inestable a pH 5,0 mientras que el tratamiento con EDTA, ácido glutámico y glutatión $5 \mathrm{mM}$ también produjeron una severa inhibición, tanto en su acción hemorrágica como en su actividad caseinolítica. En cambio, por adición de iones calcio $(10 \mathrm{mM})$ se incrementó la intensidad del área hemorrágica. CONCLUSIONES: Los ensayos de inmunodifusión e inmunoelectroforesis demostraron que el suero antibotrópico polivalente (Instituto Nacional de Salud [INS] - Lima) reconoció a la fracción hemorrágica y las pruebas de neutralización in vivo dieron como resultado la inhibición del veneno crudo, pero no de la hemorragina purificada.
\end{abstract}

Palabras clave: Botropos; veneno de crotálidos; viperidae; inmunodifusión; inmunoelectrofóresis.

\section{BIOCHEMICAL CHARACTERIZATION AND BIOLOGICAL ACTION OF AN HAEMORRHAGINE FROM THE Bothrops brazili VENOM SUMMARY}

OBJECTIVE: To characterize a hemorrhagic protein from Bothrops brazili snake venom and to determine if the polyvalent antibotropic serum is able to neutralize it. MATERIAL AND METHODS: A hemorrhagic protein from Bothrops brazili snake venom was purified through two chromatographical steps: Sephadex G-100 and CM Sephadex C-50, respectively, using 0,05M ammonium acetate buffer $\mathrm{pH}$ 7. In the last chromatographical system the protein was eluted after $0,3 \mathrm{M}$ sodium chloride was applied; thus, a unique band was achieved by PAGE-SDS. A hemorrhagic action monitored through caseinolytic activity obtained 8,4 folds of purification and the minimum hemorrhagic dose (MHD) was 6,61 ug in albine mice. RESULTS: A structural analysis of associated carbohydrates showed 8,05\% of hexoses, $11,62 \%$ of hexosamines, and $0,69 \%$ of sialic acid; its termostability was detected at $50^{\circ} \mathrm{C}$ for 10 minutes while total inhibition was observed above this. This protein was very unstable at $\mathrm{pH} 5,5 \mathrm{mM}$; EDTA, glutamic acid and glutatión had potent inhibitor effects. In contrast, $10 \mathrm{mM}$ of $\mathrm{Ca}^{+2}$ increased the hemorrhagic area. CONCLUSIONS: Both inmunodiffusion and inmunoelectrophoresis essays showed that polyvalent botropic antivenom (NIH-Lima) recognized the hemorrhagic protein. Furthermore, in vivo experiments showed that the antivenom was capable to neutralize the whole venom but not purified haemorrhagine.

Key words: Bothrops; crotalid venoms; viperidae; immunodiffusion; immunoelectrophoresis.

Correspondencia:

Dr. Armando Yarlequé

Ciudad Universitaria. Facultad de Ciencias Biológicas

Universidad Nacional Mayor de San Marcos

Venezuela Cuadra 34. Lima 1, Perú

E-mail: ayarlequec@unmsm.edu.pe 


\section{INTRODUCCIÓN}

Bothrops brazili, conocida comúnmente como "Jergón Shushupe" ( ${ }^{1}$ ) es una serpiente ponzoñosa que pertenece a la familia Viperidae, subfamilia Crotalinae. Habita en América del Sur, reportando su presencia en Brasil, Colombia, Ecuador, Guyana, Perú, Surinam y Guayana Francesa $\left({ }^{2}\right)$. En nuestro país se distribuye en los departamentos de Amazonas, Loreto, Madre de Dios y Ucayali. Esta serpiente presenta foceta loreal, importante órgano termoreceptor, lo cual es una característica taxonómica de las especies de la subfamilia Crotalinae. Además tiene contextura robusta, con una longitud promedio de 1,20 m. El dorso de estos animales es de color pardo con dibujos oscuros en forma de triángulo, los cuales tienen manchas en su vértice. El vientre es de color crema y se le ubica frecuentemente en la floresta primaria. Sus alimentos principales son roedores y lagartijas. Tienen fecundación interna y reproducción ovovivípara $\left({ }^{3}\right)$. Se conoce que la característica más importante del Bothrops brazili es la de producir abundante cantidad de veneno en sus glándulas en comparación con otros vipéridos $\left({ }^{4}\right)$, calculándose que puede inyectar hasta $4 \mathrm{~mL}$ de veneno en una mordedura. Por ello, un caso de ofidismo causado por Bothrops brazili tiene graves consecuencias, tanto por los componentes tóxicos presentes en su veneno como por el volumen que puede inocular.

Se sabe que la sintomatología de un envenenamiento botrópico, es decir, aquel accidente causado por especies del género Bothrops, tiene las siguientes características: dolor intenso en la zona afectada, hemorragia, formación de edema, descenso de la presión arterial, aparición del síndrome de coagulación intravascular diseminada, hemólisis y posterior necrosis. Estas alteraciones, cuando el accidente es causado por Bothrops brazili, pueden ser más graves, especialmente en cuanto a la hemorragia; de allí que el tratamiento clínico debe ser rápido y adecuado para atender estos casos.

Escobar y col, en $1996\left(^{5}\right)$, reportaron la presencia de una enzima proteolítica con ac- ción sobre fibrinógeno y efecto hemorrágico, la cual estaba presente en el veneno de $B$. brazili. Por su parte, Azañero y col, en 1996 $\left({ }^{6}\right)$, estudiaron dicha enzima, encontrando que tenía acción sobre la fibrina y el fibrinógeno, llamándola enzima fibrinogenolítica. El estudio de esta proteína en cuanto a su acción hemorrágica fue sólo explorativo. Se define la hemorragia como la ruptura de las paredes de los vasos sanguíneos por compuestos llamados factores, principios hemorrágicos o hemorraginas $\left(^{7}\right)$, produciendo la salida de sangre en los vasos dañados. Las hemorraginas atacan las células endoteliales de los vasos sanguíneos, degradan las proteínas de los componentes de la lámina basal como de la matriz extracelular $\left({ }^{8}\right)$. Muchas hemorraginas degradan dichos vasos sanguíneos con patrones patológicos celulares similares, como la destrucción de la membrana plasmática, la desorganización de la lámina basal, entre otros $\left({ }^{9,10}\right)$. Como consecuencia de ello, la víctima sufre un desequilibrio local o sistémico $\left({ }^{11}\right)$. Debido a las importantes funciones que realiza la sangre, la hemorragia es uno de los síntomas más severos que se presenta durante un cuadro de ofidismo, siendo tan grave que por sólo esta causa una persona puede fallecer, puesto que la falta de metabolitos y especialmente la carencia de oxígeno produce daños irreversibles en órganos vitales.

Por tanto, el motivo de la presente investigación fue caracterizar la hemorragina aislada de B. brazili y determinar si el suero antibotrópico polivalente es capaz de neutralizarlo.

\section{MATERIAL Y MÉTODOS}

El veneno de $B$. brazili fue obtenido de especímenes procedentes de la zona del Alto Marañón, departamento de Amazonas, y mantenidos en el Serpentario "Oswaldo Meneses" del Museo de Historia Natural de la UNMSM.

La concentración de proteínas fue estimada alternativamente por la D.O. a $280 \mathrm{~nm}$ en un espectrofotómetro Shimadzu y por el método de 
Lowry et al. $\left({ }^{12}\right)$ usando albúmina sérica bovina como proteína estándar. La actividad proteolítica fue determinada por el método de Takahashi y Ohsaka $\left({ }^{13}\right)$, usando como substrato caseína al $2 \%$ en buffer Tris $\mathrm{HCl} 0,2 \mathrm{M}$ a $\mathrm{pH} 8,5$. Los productos ácido solubles obtenidos por acción enzimática fueron medidos a $280 \mathrm{~nm}$.

La actividad hemorrágica se llevó a cabo inoculando por vía intraperitoneal ratones albinos de $20-22 \mathrm{~g}$ soluciones de $0,1 \mathrm{~mL}$ de veneno crudo y de la hemorragina purificada, siguiendo el método de Kondo $\left({ }^{14}\right)$ modificado por Lomonte et al $\left({ }^{15}\right)$. Luego de dos horas, los ratones fueron sacrificados, determinándose el área hemorrágica formada, para lo cual se midió el diámetro mayor de cada área. La dosis mínima hemorrágica (DHM) correspondió a la cantidad de muestra que produce un área hemorrágica de $10 \mathrm{~mm}$ de diámetro obtenida al graficar las dosis de muestras en escala logarítmica versus el diámetro de las áreas producidas expresadas en milímetros.

La purificación de la hemorragina se realizó de acuerdo con la técnica desarrollada por Azañero y col $\left({ }^{6}\right)$. Para ello se preparó una muestra que contenía $50 \mathrm{mg} / \mathrm{mL}$ de veneno de Bothrops brazili en buffer acetato de amonio $0,05 \mathrm{M}$ a pH 7,0 , removiéndose los restos insolubles por centrifugación a $4000 \mathrm{rpm}$ por 15 minutos. La fracción soluble fue aplicada a una columna de filtración molecular en Sephadex G$100(17,9 \times 2,1 \mathrm{~cm})$ equilibrada con el mismo buffer, colectándose fracciones de $2 \mathrm{~mL}$. En cada fracción se determinó la absorbancia a $280 \mathrm{~nm}$ y la actividad sobre caseína. Las fracciones del segundo pico con mayor actividad proteolítica fueron juntadas y aplicadas a una columna de CM-Sephadex C-50 (14,6 x 1,2 cm) equilibrada con el mismo buffer, aplicándose después de dos volúmenes de buffer inicial una solución de cloruro de sodio $0,3 \mathrm{M}$ y luego a $0,6 \mathrm{M}$ para desprender la proteína asociada al sistema. En cada fracción se midió la actividad proteolítica y la acción hemorrágica. El pool que contenía a la hemorragina aislada fue sometido al análisis electroforético en PAGE-SDS para determinar la pureza de la preparación de acuerdo con la técnica de Weber y Osborn $\left({ }^{16}\right)$.

Con respecto a las propiedades de la proteína en estudio, el contenido de carbohidratos asociados a la hemorragina fue analizado por el método de Winzler, $\left({ }^{17}\right)$ para hexosas y hexosaminas, habiéndose usado el método de Warren $\left({ }^{18}\right)$ para la determinación de ácido siálico.

La estabilidad térmica de la proteína fue evaluada en un rango de temperatura de 37 a $70^{\circ} \mathrm{C}$. Para ello se preparó alícuotas de $0,5 \mathrm{~mL}$ de muestra, incubándose los tubos por 10 minutos a $37,50,60$ y $70^{\circ} \mathrm{C}$. Luego de que las muestras se enfriaron a temperatura ambiente, se midió la actividad hemorrágica con $0,1 \mathrm{~mL}$ equivalente a 10 ug de la hemorragina.

Para observar el efecto del $\mathrm{pH}$, se tomó una muestra de hemorragina $0,5 \mathrm{~mL}$ en buffer acetato de amonio $0,05 \mathrm{M} \mathrm{pH} \mathrm{7,0} \mathrm{y} \mathrm{se} \mathrm{la} \mathrm{colocó} \mathrm{en} \mathrm{una}$ bolsa de diálisis, efectuándose este procedimiento por 12 horas a temperatura ambiente con tres cambios de solvente, que en este caso fue buffer acetato de amonio 0,1M pH 5,0. Luego se determinó la actividad usando 22 ug de proteína. Así mismo, se evaluó la capacidad de hemorragina para hidrolizar ésteres sintéticos, como p-Tosyl arginil metil éster (TAME) y el colágeno bajo la forma de azocoll. En el primer caso, se incubó $3 \mathrm{~mL}$ de TAME $0,12 \mathrm{mM}$ en buffer Tris $\mathrm{HCl} 0,05 \mathrm{M}$ pH 7,5 con $0,1 \mathrm{~mL}$ de la proteína en estudio y luego se siguió espectrofotometricamente el incremento de absorbancia a $247 \mathrm{~nm}$, de acuerdo con la técnica de Schwert y Takenaka $\left({ }^{19}\right)$. En el segundo caso se usó $1,9 \mathrm{~mL}$ de azocoll $(2 \mathrm{mg} / \mathrm{mL})$ en buffer Tris $\mathrm{HCl} 0,1 \mathrm{M}$ pH 8,0 y 0,1 de muestra $(1 \mathrm{mg} / \mathrm{mL})$. La muestra se incubó a $37^{\circ} \mathrm{C}$ por 20 minutos y luego se añadió $1 \mathrm{~mL}$ de ácido tricloroacético $0,44 \mathrm{M}$ para medirse la absorbancia a $520 \mathrm{~nm}$, siguiendo el método de Chavira et al $\left({ }^{20}\right)$ modificado por Rodríguez y Yarlequé $\left({ }^{21}\right)$.

La actividad específica fue expresada en unidades por minuto por $\mathrm{mg}$ de proteína. Una uni- 
dad de actividad se define como la cantidad de enzima capaz de liberar grupos azo equivalente a una unidad óptica de 0,001 por minuto a $520 \mathrm{~nm}$.

En cuanto a la influencia de algunos agentes químicos sobre la actividad hemorrágica, se utilizó concentraciones $5 \mathrm{mM}$ de EDTA, mercaptoetanol, ácido glutámico, glutatión, así como de los iones divalentes $\left(\mathrm{Ca}^{+2}, \mathrm{Mg}^{+2}, \mathrm{Mn}^{+2}\right.$ y $\mathrm{Zn}^{+2}$ ) bajo la forma de cloruros. Mezclas que contenían cada uno de los agentes más la hemorragina ( $14 \mathrm{ug}$ ) fueron preincubadas a $37^{\circ} \mathrm{C}$ por 10 minutos, después de lo cual se determinó la actividad hemorrágica en cada muestra.

Adicionalmente, se efectuó ensayos para probar la antigenicidad de la proteína aislada. Para ello se realizó pruebas de inmunodifusión usando agarosa al $1 \%$ en buffer Veronal $0,08 \mathrm{M} \mathrm{pH}$ $8,2{ }^{(22)}$.

En láminas portaobjetos se colocó $3 \mathrm{~mL}$ de agarosa y luego se hizo agujeros de $3 \mathrm{~mm}$ de diámetro y en los agujeros periféricos se colocó 2 ul de hemorragina $(0,370 \mathrm{mg} / \mathrm{mL})$, veneno crudo $(10 \mathrm{mg} / \mathrm{mL})$ y albúmina bovina $(0,1 \mathrm{mg} /$ $\mathrm{mL}$ ), respectivamente, mientras que en el agujero central se colocó 2 uL del suero antibotrópico polivalente (concentrado) preparado por el INS-Lima. Luego de colocar las láminas en cámara húmeda a temperatura ambiente por 22 horas, ellas fueron secadas a $50^{\circ} \mathrm{C}$, teñidas con azul brillante de Coomasie $0,5 \%$ y decoloradas con metanol-ácido acético hasta visualizar las líneas de precipitación.

Para los ensayos de inmunoelectroforesis, se preparó láminas con agarosa al $1 \%$ y en cada lado de la lámina se hizo perforaciones de 1 x 4 $\mathrm{mm}$, colocándose $2 \mathrm{uL}$ de la hemorragina $(0,370$ $\mathrm{mg} / \mathrm{mL})$ y el veneno crudo $(10 \mathrm{mg} / \mathrm{mL})$, respectivamente, para luego someterlo a una corrida electroforética por una hora con una intensidad de corriente de $6 \mathrm{~mA}$ por hora. Inmediatamente después se hizo una canaleta central de $56 \times 1 \mathrm{~mm}$, en donde se colocó el suero antibotrópico polivalente, procediéndose a dejar las láminas en cámara húmeda durante 48 horas. Luego de lo cual se las coloreó con azul brillante de Coomasie al 0,5\% y se efectuó la decoloración, tal como el caso anterior, para determinar las áreas de precipitación.

Finalmente, la hemorragina fue sometida al análisis de neutralización in vivo con el suero antibotrópico polivalente. Para ello, se preparó preincubados que contenían $10 \mathrm{uL}$ de suero con $18,36,54 \mathrm{ug}$ de veneno crudo y en paralelo con 10 ó 20 ug de hemorragina. Luego de la preincubación por una hora a $37^{\circ} \mathrm{C}$, se tomó volúmenes de $0,1 \mathrm{~mL}$ que fueron inyectados por vía intraperitoneal a ratones albinos para medir la actividad hemorrágica en cada caso. La dosis de neutralización del suero antibotrópico Instituto Nacional de Salud (INS)-Lima indican que $10 \mathrm{~mL}$ del antiveneno neutralizan $32 \mathrm{ug}$ de veneno botrópico.

\section{RESULTADOS}

\section{Aislamiento de la hemorragina de Bothrops brazili}

Las Figuras 1 y 2 resumen el procedimiento cromatográfico que permitió la purificación de la hemorragina en estudio, habiéndose usado la medida de la actividad caseinolítica para seguir su acción. Esta proteína se obtuvo en la cromatografía de filtración sobre Sephadex-G100 en el segundo pico, y luego de pasar esta fracción por CM-Sephadex C50 a pH 7,0 la proteína hemorrágica fue recuperada al adicionarle al buffer de corrida $\mathrm{NaCl}$ 0,3 $\mathrm{M}$.

Usando ambos pasos cromatográficos, se obtuvo una purificación de 8,4 veces, un rendimiento de $97,5 \%$ y se recuperó $5,006 \mathrm{mg}$ de proteína activa, equivalente a $11,64 \%$ de la proteína total (Tabla 1). Así mismo, empleando la técnica de PAGE-SDS en presencia de 2mercaptoetanol, se demostró que la hemorragina era una entidad homogénea constituida por una sola cadena polipeptídica. Por otro lado, la determinación de la dosis hemorrágica mínima (DHM), efectuada tanto en el veneno crudo como en la proteína aislada, dió valores de 6,17 ug y 6,61 ug, respectivamente. 


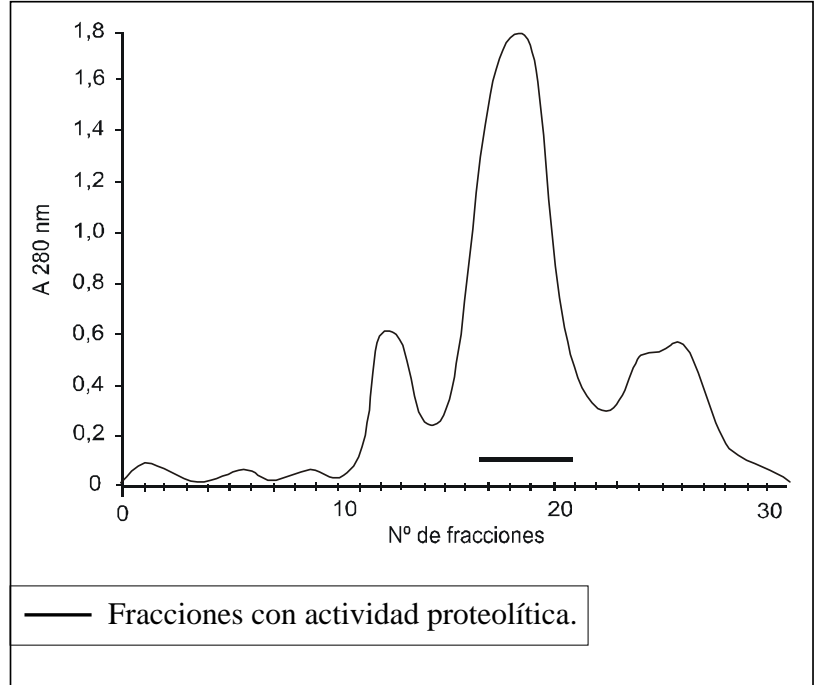

Figura 1.- Cromatografía de filtración en Gel: Sephadex G-100.

\section{Presencia de carbohidratos}

En la Tabla 2 se muestra los datos obtenidos al medir cuantitavamente los carbohidratos asociados tanto al veneno crudo como a la hemorragina. Se puede apreciar que el porcentaje de hexosas para la proteína purificada fue de $8,05 \%$, mientras que para hexosaminas fueron $11,62 \%$ y $0,69 \%$ para ácido siálico. En cambio, en el veneno crudo se obtuvo valores porcentuales de $0,99 \%$ para hexosas, $0,79 \%$ para hexosaminas y $0,24 \%$ para ácido siálico. Por tanto, podemos decir que la proteína hemorrágica es una glicoproteína básica.

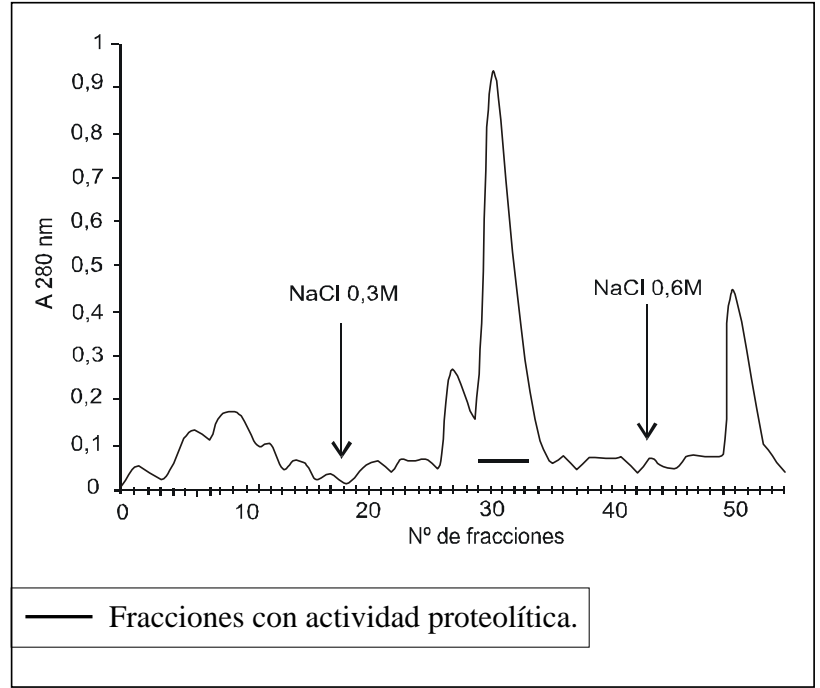

Figura 2.- Cromatografía de intercambio iónico: CM-Sephadex C-50.

\section{Estabilidad a la temperatura y el pH}

Los ensayos en animales de experimentación mostraron que la actividad hemorrágica se reduce en un $50 \%$ aproximadamente al incubarse la proteína a $50^{\circ} \mathrm{C}$ por 10 minutos en lugar de $37^{\circ} \mathrm{C}$. En cambio, temperaturas de 60 y $70^{\circ} \mathrm{C}$, respectivamente, anularon la acción hemorrágica.

Así mismo, la proteína hemorrágica fue estable a pH 7,0 durante 6 semanas a temperatura ambiente, pero se inactivó completamente en 1 hora al colocarla en un medio ácido de pH 5,0.

Tabla 1.- Purificación de la hemorragina de Bothrops brazili.

\begin{tabular}{|c|c|c|c|c|c|c|}
\hline & \multicolumn{2}{|c|}{ Proteína } & \multirow[t]{2}{*}{ Actividad específica } & \multirow[t]{2}{*}{ Purificación } & \multirow[t]{2}{*}{ U.T.A } & \multirow[t]{2}{*}{ Rendimiento } \\
\hline & $\mathrm{mg}$ & $\%$ & & & & \\
\hline Crudo & 43,020 & 100,00 & 0,47364 & 1,000 & 20,376 & $100,00 \%$ \\
\hline Sephadex G-100 & 10,372 & 24,11 & 1,34643 & 2,843 & 13,965 & $68,54 \%$ \\
\hline CM Sephadex C-50 & 5,006 & 11,64 & 3,97025 & 8,382 & 19,875 & $97,5 \%$ \\
\hline
\end{tabular}

U.T.A: Unidad total de actividad proteolítica. 
Tabla 2.- Determinación de carbohidratos.

\begin{tabular}{lcc}
\hline $\begin{array}{l}\text { Muestra } \\
\text { carbohidratos }\end{array}$ & Veneno crudo & Hemorragina \\
\hline Hexosas & $0,99 \%$ & $8,05 \%$ \\
Hexosaminas & $0,79 \%$ & $11,62 \%$ \\
Ácido siálico & $0,24 \%$ & $0,69 \%$ \\
\hline
\end{tabular}

\section{Efecto de agentes químicos}

El tratamiento con el agente quelante EDTA, el ácido glutámico y el glutatión a concentraciones de $5 \mathrm{mM}$ produjeron una inhibición total de la hemorragina, tanto en su capacidad para hidrolizar la caseína como para inducir hemorragia en ratones albinos. En cambio, la adición de 2-mercaptoetanol o de los iones divalentes $\mathrm{ZN}^{+2}, \mathrm{Mg}^{+2}$ y $\mathrm{Mn}^{+2}$ no afectaron la actividad de la proteína. En contraste, los iones $\mathrm{Ca}^{+2}$, aún cuando no incrementaron el área hemorrágica, sí produjeron mayor intensidad en el sangrado (Tabla 3).

Tabla 3.- Efectos de algunos agentes químicos sobre la hemorragina.

\begin{tabular}{lc}
\hline Agentes químicos & Área hemorrágica (\%) \\
\hline Control (B. acetato de & 100 \\
amonio 0,025 m) & 0 \\
EDTA $(5 \mathrm{~mm})$ & 0 \\
Ácido glutámico $(5 \mathrm{~mm})$ & 0 \\
Glutatión $(5 \mathrm{~mm})$ & 100 \\
Mercaptoetanol $(5 \mathrm{~mm})$ & 100 \\
Zinc $(5 \mathrm{~mm})$ & 100 \\
Magnesio $(5 \mathrm{~mm})$ & 100 \\
Manganeso $(5 \mathrm{~mm})$ & \\
\hline
\end{tabular}

\section{Antigenicidad y neutralización}

Los ensayos de inmunodifusión e inmunoelectroforesis. en los que se enfrentó a la proteína aislada contra el suero antibotrópico polivalente, revelaron una sola línea o arco de precipitación, respectivamente, lo que demuestra que la proteína en estudio es antigénicamente reconocida por el antiveneno (Figuras 3 y 4 ). Sin embargo, los ensayos de neutralización, en los que se hizo preincubados del suero con la proteína hemorrágica, indicaron que, a diferencia de lo que ocurre con el veneno crudo de $B$. brazili, la hemorragina no es neutralizada por el antídoto.

\section{DISCUSIÓN}

Aun cuando se sabe que los venenos botrópicos sudamericanos causan efectos biológicos muy notorios, como edema, hemorragia, coagulación intravascular diseminada, hipotensión y necrosis, cada uno de ellos tiene como origen componentes bioactivos específicos que están presentes en forma típica en la ponzoña y que, como la mayoría, son compuestos de naturaleza proteica. Las variantes que se encuentra en la composición química de un veneno son consecuencia del proceso de síntesis proteica a nivel glandular en las serpientes y los mecanismos que controlan este proceso molecular $\left({ }^{23,24}\right)$ de allí que se puede entender, por ejemplo, que el veneno de $B$. atrox, que habita en la floresta amazónica de Brasil, disponga de una potente fosfatasa alcalina; mientras que la que vive en la zona de Ucayali-Perú, prácticamente carece de esta proteína $\left({ }^{25}\right)$.

Diferencias significativas en la composición de veneno también se ha encontrado en la especie L. muta localizada en Brasil, Perú y Costa Rica y, tal vez lo más notorio, en este caso está relacionado con la enzima similar a trombina, cuya mayor potencia fue determinada en la especie peruana $\left({ }^{26}\right)$.

En el caso de B. brazili, uno de los efectos biológicos más severos observados clínicamente es la profusa hemorragia que causa este veneno. Dado que la dosis hemorrágica mínima (DHM) se incrementa muy ligeramente al medirla usando la proteína purificada con respecto al crudo, se puede colegir que el efecto observado, tanto en humanos como en animales de laboratorio, corresponde a una elevada fracción 


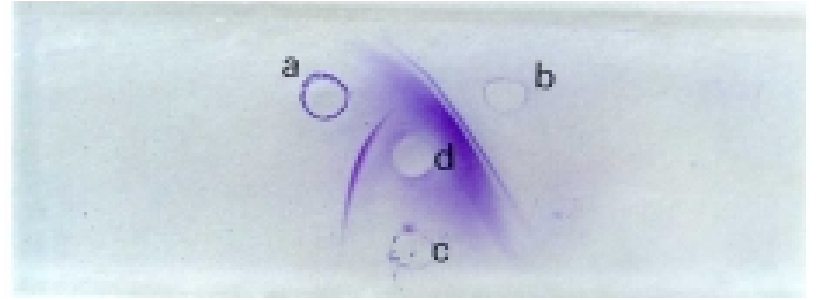

Figura 3.- Prueba de inmunodifusión.

(a) Hemorragina purificada $(0,225 \mathrm{mg} / \mathrm{mL})$. (b) Veneno crudo $(10 \mathrm{mg} / \mathrm{mL})$.

(c) Albúmina bovina $(0,1 \mathrm{mg} / \mathrm{mL})$.

(d) Suero antibotrópico (sin diluir).

del veneno con esta actividad. Esto quiere decir que, por su potencia, la acción hemorrágica es prácticamente la misma tanto en la ponzoña total como en la proteína aislada luego de 2 pasos cromatográficos.

El hecho de que se haya podido purificar la hemorragina mediante los 2 pasos antes indicados, sugiere en primer lugar que, tratándose de una proteína básica, su acción sería muy intensa en tejidos acompañados de fluidos neutros o alcalinos, teniendo los carbohidratos asociados un rol activador de esta acción.

Por otro lado, la actividad hemorrágica parcial detectada a $50^{\circ} \mathrm{C}$ sería un elemento a considerar en la reducción del efecto tóxico de este veneno a través de la hemorragina, mas no en su inactivación. Dicho de otra manera, en casos probables en que la serpiente deba resistir temperaturas de esta magnitud, su veneno perdería parte de su acción hemorrágica sin que ésta se anulara.

En cuanto a los agentes químicos ensayados, es interesante notar la fuerte acción inhibidora del EDTA, agente quelante que probablemente extrae algún ión metálico asociado a la actividad hemorrágica. Pero, tal vez es más significativa la inhibición obtenida con el ácido glutámico y el tripéptido glutatión, puesto que en estudios previos realizados en este laboratorio tanto el aminoácido como el tripéptido indicado tuvieron una alta eficiencia para inhibir

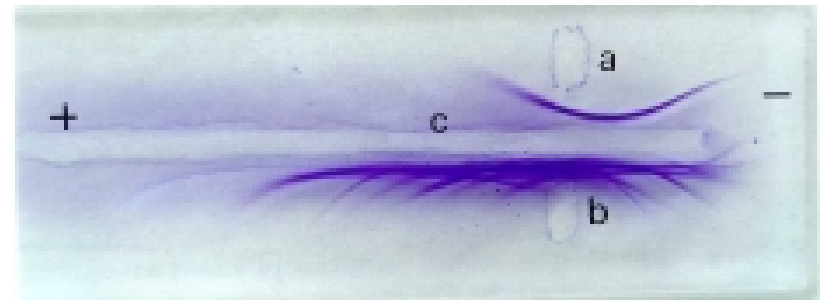

Figura 4.- Prueba de inmunoelectroforesis. (a) Hemorragina purificada $(0,225 \mathrm{mg} / \mathrm{mL})$. (b) Veneno crudo $(10 \mathrm{mg} / \mathrm{mL})$.

(c) Suero antibotrópico (sin diluir).

varios venenos vipéridos. Así como la actividad de la enzima similar a trombina y las proteinasas I y II de la $L$. muta $\left({ }^{21,27}\right)$, el mecanismo de esta inhibición es aún desconocida.

Con respecto a la acción de los iones $\mathrm{Mg}^{+2}$, $\mathrm{Mn}^{+2}, \mathrm{Zn}^{+2}$ y $\mathrm{Ca}^{+2}$, podemos decir que aquellos mas bien incrementarían la acción hemorrágica, lo que descarta por lo menos para este caso el uso empírico de agentes como el gluconato de calcio empleado como antiveneno en algunas regiones de la selva peruana. Como se ha observado, el ion $\mathrm{Ca}^{+2}$ específicamente aumenta la intensidad hemorrágica, aunque no necesariamente el área producida.

Finalmente, un aspecto que llama mucho la atención es que si bien es cierto la hemorragina es fuertemente antigénica y, por tanto, forma líneas típicas de precipitación con el antiveneno botrópico polivalente, al parecer es poco sensible a la neutralización in vivo, lo cual significaría que el efecto biológico podría ser prolongado con las consecuencias ya descritas, aún luego de la aplicación del antiveneno. Obviamente, la presente investigación será ampliada enfocando este punto.

\section{BIBLIOGRAFÍA}

1. Hoge RA, S A R W L Hoge Romano. Poisonous snakes of the world. Parte I. Check list of the Pit Vipers, Viperoidea, Viperidae, Crotalidae. Mem Inst Butantan 1978-1979; 42/ 43: $179-310$. 
2. Campbell J, Lamar W. The venomous reptiles of Latin America. New York, Crustock Publishing Associated, USA. 1989.

3. Carrillo de Espinoza, Icochea J. Lista taxonómica preliminar de los reptiles vivientes del Perú. Publicación Mus. Hist Nat "Javier Prado" UNMSM (A) 1995. 30:51.

4. Zavaleta A. Producción de veneno cristalizado de serpientes en el Instituto Nacional de Salud (Lima-Perú): Período 1970-1986. Rev Méd Herediana 1992; 3: 87.

5. Escobar E, Rodríguez E, Yarlequé A. Aislamiento y estudio bioquímico de una proteasa del veneno de Bothrops brazili. Libro Resúmenes V Reunión Científica del ICBAR UNMSM. 1996: 56.

6. Azañero M. Caracterización bioquímica de una enzima fibrinogenolítica del veneno de Bothrops brazili «Jergón shushupe» y su comparación con la estreptoquinasa de Streptococcus. Tesis para optar el título profesional de Biólogo UNMSM. 1996.

7. Tu A. Tissue damaging effects by snake venoms: hemorrhage and mionecrosis. En: Handbook of Natural Toxins. Volume 5. Reptile venoms and toxins, edited by Anthony Tu. New York-USA: Marcel Dekker Inc. 1991.

8. Kamiguti AS, Hay CRM, Theakston RDG, Zuzel M. Insights into the mechanism of haemorrhage caused by snake venom metalloproteinases. Toxicon 1996; 34(6): 627-42.

9. Ownby CL, Bjarnarson J, Tu AT. Hemorrhagic toxin from rattlesnake (Crotalus atrox) venom: Pathogenesis of hemorrhage induced by three purified toxins. Am J Pathol 1978; 93: 201-08.

10. Ownby CL, Geren CR. Pathogenesis of hemorrhage induced by hemorrhagic proteinase IV from timber rattlesnake (Crotalus horridud horridus) venom. Toxicon 1987; 25: 517-26.

11. Tu A, Homma M. Toxicologic study of snake venoms from Costa Rica. Toxicol Appl Pharmacol 1970; 16: 73-8.

12. Lowry O, Rosebrough N, Farr A, Randall R. Protein measurement with the folin phenol reagent. J Biol-Chem AÑO; 193: 265-75.

13. Takahashi T, Ohsaka A. Purification and characterization of proteinase in the venom of Trimeresurus flavovirides. Complet separation of the enzymes from hemorrhagic activity. Biochem Biophys Acta 1970; 198-293.

14. Kondo H, Kondo S, Ikesawa M, Muta R, Ohsaka A. Studies on the cuantitative method for determination of hemorrhagic activity of Habu snake venom. Japan J Med Sci Biol 1960; 13: 43.

15. Lomonte B, Cerdas L, Gene J, Gutierrez JM. Neutralization of local effects of the terciopelo (Bothrops asper) venom by blood serum of the colubrid snake Clelia clelia. Toxicon 1982; 20 (3): 571-9.

16. Webern K, Osborn M. The realiability of molecular weight determinations by dodecil sulphate polyacrylamide gel electrophoresis. J Biol Chem 1969; 244: 4406-12.

17. Winzler R. Determinations of serum glycoproteins. En: Methods of Biochemical Analysis 1995; 2: 279-311.

18. Warren $\mathbf{L}$. The thiobarbituric acid assay of sialic acids. J Biol Chem 1959; 234 (8): 1971-5.

19. Schwert G, Takenaka A. Spectrophotometric determination of trypsin and chimotrypsin. Biochem Biophys Acta 1955; 16: 570 .

20. Chavira R, Burnett J, Hageman J. Assaying proteinases with azocoll. Analytical Biochemistry 1984; 136: 446.

21. Rodríguez E, Yarlequé A. Purification and characterization of two proteinases from bushmaster Lachesis muta snake venom. Third Pan-American Symposium on animal, plant and microbial toxins. Oaxtupec, Morelos State México, 912 January 1990. Toxicon 1990; 28 (6): 621-2.

22. Ouchterlony O, Nilsson LA. Immunodifussion and inmunoelectrophoresis. Handbook of Experimental Immunology I. 1967; (34): 655-60.

23. Yarlequé A. Las serpientes peruanas y sus venenos. LimaPerú: Fondo Editorial UNMSM. 2000. 78 pag.

24. Russell F. Snake venoms poisoning. New York: Scholium International, Inc. 1983: 5-61.

25. Yarlequé A, Escobar E, Campos S. Exonucleasas y otras actividades nucleóticas en los venenos de serpientes de Lachesis muta y Bothrops atrox. Acta Científica Venezolana 1983; 34: 336.

26. Campos S, Escobar E, Lazo F, Yarlequé A, Creighton B, Gaffney P, Marsh N, Peyser P and Whaler B. Partial separation of thrombin like enzyme from the venom of the Peruvian Bushmaster snake Lachesis muta muta. En: Haemostasis and Animal Venoms. New York: Marcel Dekker Inc. 1988; 7 (8): 107-15.

27. Roncalla R, Yarlequé A. Efecto del ácido glutámico sobre algunas enzimas de los venenos de serpientes. Bol Soc Quím Perú AÑO; 51 (1): 38-47. 